\title{
Molecular Characterization of Vegetative Compatibility Group 4A and 4B Isolates of Verticillium dahliae Associated with Potato Early Dying
}

\author{
K. F. Dobinson, Agriculture and Agri-Food Canada, London, ON, Canada N5V 4T3; M. A. Harrington, Depart- \\ ment of Plant Sciences, University of Western Ontario, London, ON, Canada N6A 5B7; and M. Omer and R. C. \\ Rowe, Department of Plant Pathology, Ohio State University, Ohio Agricultural Research and Development Center, \\ Wooster 44691
}

\begin{abstract}
Dobinson, K. F., Harrington, M. A., Omer, M., and Rowe, R. C. 2000. Molecular characterization of vegetative compatibility group 4A and 4B isolates of Verticillium dahliae associated with potato early dying. Plant Dis. 84:1241-1245.

Forty isolates of Verticillium dahliae, collected from potato seed tubers and potato plants from various regions in North America and previously assigned to vegetative compatibility groups (VCGs) $4 \mathrm{~A}$ or $4 \mathrm{~B}$, were characterized using molecular markers. The VCG 4A isolates were previously shown to be a highly virulent pathotype of potato and to interact synergistically with the root-lesion nematode Pratylenchus penetrans to cause potato early dying. All but one of the VCG 4A isolates characterized in this study lacked the subspecies-specific repetitive DNA sequence E18 and could be differentiated from the remaining isolates by restriction fragment length polymorphisms (RFLPs) in the nuclear rDNA and Trp1 loci. The E18 RFLP patterns of several VCG 4B isolates from Maine and New York were highly similar to those of VCG 4B isolates previously collected from potato and tomato fields in Ontario. The data presented here suggest that the molecular markers will be useful for the detection and classification of isolates of $V$. dahliae associated with potato early dying.
\end{abstract}

Additional keywords: DNA fingerprints, PED

The soilborne fungus Verticillium dahliae Kleb. causes vascular wilt disease in a variety of economically important agronomic and horticultural crops and is the principal pathogen responsible for potato early dying (PED) in North America (23). Strains of $V$. dahliae that are associated with this disease can be classified into a few subspecific groups $(9,10,12,16,20,21,25)$. These groups are differentiated on the basis of vegetative compatibility, a multigene trait that determines the capacity of distinct fungal isolates within a species to anastomose and form heterokaryons, and to potentially exchange genetic information $(13,14)$. Because $V$. dahliae has no known sexual reproductive cycle, isolates in a single vegetative compatibility group (VCG) are thought to comprise a biologically distinct population, members of which often share specific traits. Four ma-

Corresponding author: K. F. Dobinson

E-mail: dobinsonk@em.agr.ca

Current address of M. A. Harrington: Agriculture and Agri-Food Canada, Saskatoon Research Centre, 107 Science Place, Saskatoon, SK Canada S7N 0X2.

Accepted for publication 2 August 2000.

Publication no. D-2000-0915-01R

(C) 2000 Department of Agriculture and Agri-

Food, Government of Canada jor VCGs have been identified within $V$. dahliae; VCGs 2 and 4 have been further divided into subgroups based on differential interactions among tester strains within each group $(9,10)$. VCG 2 includes subgroups $2 \mathrm{~A}$ and $2 \mathrm{~B}$, while VCG 4 includes subgroups $4 \mathrm{~A}, 4 \mathrm{~B}$, and $4 \mathrm{~A} / \mathrm{B}$. The majority of isolates associated with PED are in VCGs $4 \mathrm{~A}$ and $4 \mathrm{~B}(1,10,25)$. Although there is considerable variation in the aggressiveness of individual isolates of $V$. dahliae on potato, the VCG $4 \mathrm{~A}$ isolates are of the most concern to potato production in North America, as they are more aggressive than VCG 4B isolates $(10,20$, $21,25)$ and interact synergistically with the root-lesion nematode Pratylenchus penetrans, resulting in premature plant senescence and low tuber yields (1).

Vegetative compatibility analysis, the only method currently available to differentiate isolates of $V$. dahliae associated with PED, is a laborious procedure that requires generation of nitrate nonutilizing (nit) mutants, mutant phenotype characterization, and multiple complementation tests $(9,10,25)$. The assignment of an isolate to a specific VCG may also be complicated by the inability to obtain suitable nit mutants, or by differences in the ability of a particular nit mutant to complement different tester strains within a VCG $(9,25)$. Studies of potato early dying would therefore be facilitated if additional methods could be developed to rapidly differentiate the VCG 4A isolates from isolates in other subgroups of $V$. dahliae.

Omer et al. reported that both VCG 4A and $4 \mathrm{~B}$ isolates of $V$. dahliae frequently can be recovered from commercial potato seed tubers produced in North America $(20,21)$. Data from recent molecular studies of $V$. dahliae have suggested that potato may act as a reservoir for the VCG $4 \mathrm{~A}$ and $4 \mathrm{~B}$ isolates that are prevalent in some potato and tomato fields in Ontario, Canada, and that specific molecular markers may be diagnostic for the VCG 4A isolates $(5,7,8,16)$. The objectives of the current study were therefore to evaluate the strength of the association of VCG 4A with selected molecular markers and to characterize, at the molecular level, a collection of $V$. dahliae isolates from potato seed tubers from across North America.

\section{MATERIALS AND METHODS}

Verticillium isolates. $V$. dahliae tester strains Dvd-2 (VCG 4B, from tomato), Dvd-T5 (VCG 2A, from tomato; ATCC 201177), Dvd-3 (VCG 4B, from potato), and Dvd-E6 (VCG 4A, from eggplant) are from Ontario, Canada $(5,6)$. Tester strains MT (VCG 4B, from maple), BB (VCG 4A, from potato), and CW (VCG 4A/B, from cherry) are from Canada, Idaho, and Washington State, respectively (9). All other isolates of $V$. dahliae are from commercial potato seed tubers grown in 10 U.S. states and two Canadian provinces, or from potato plants from Ohio, and are listed in Table 1.

Vegetative compatibility analysis. Isolates listed in Table 1 were assigned to VCGs $4 \mathrm{~A}$ or $4 \mathrm{~B}$ in previous studies (21; M. Omer and R. C. Rowe, unpublished). Vegetative compatibility groups of potato isolates 99-1 and 66-12 were retested using the nit mutants generated by Omer et al. (21). The nit mutants were selected by growth on cornmeal agar medium containing 20 to $30 \%$ potassium chlorate, and chlorate-resistant sectors were subcultured onto minimal medium. Colonies with thin, nonaerial mycelial growth were considered to be nit mutants; mutant phenotypes were determined by growth on minimal media amended with various nitrogen sources, as previously described $(9,10)$. For VCG tests, the mutants were paired on minimal medium containing $0.2 \%$ sodium nitrate $(5,9,10)$ with complementary mutants of 
tester strains BB, MT, CW, Dvd-3, or DvdE6. Compatibility was detected as a region of dense prototrophic growth, often associated with abundant microsclerotia production, at the contact site between mycelia of the paired isolates, as described previously (9).

Restriction fragment length polymorphism (RFLP) analysis. Isolates of $V$. dahliae shown in Table 1 were characterized by RFLP analysis, using molecular markers, in a blind study in which VCG designations of the isolates were not disclosed prior to the analysis. Genomic DNA from each isolate was purified by a glass bead breakage method, from spores grown in liquid complete medium (4). The DNA was digested with the restriction enzymes EcoRI or XhoI, fractionated by electrophoresis through $0.8 \%$ agarose gels, and DNA blots prepared for hybridization as previously described (5). Highstringency hybridizations and washes, and detection of hybridized probe, were carried out as previously described (5). Hybridization probes were: (i) plasmid pTZ19/VtITS, which contains the nuclear ribosomal DNA intervening transcribed spacer and 5.8S rDNA sequences from Verticillium tricorpus (15), (ii) E18, a nuclear repetitive DNA sequence from the Dvd-2 race 2 tomato isolate of $V$. dahliae (22), and (iii) a 364-bp restriction fragment of the putative trypsin gene $\operatorname{Trp} 1$ (K. F. Dobinson, unpublished) from the Dvd-T5 race 1 isolate of $V$. dahliae, cloned into

Table 1. Origin, molecular variation, and vegetative compatibility groups (VCGs) among isolates of Verticillium dahliae collected from potato seed tubers and plants in North America

\begin{tabular}{|c|c|c|c|c|c|}
\hline Isolate $^{\mathrm{a}}$ & $\underset{\text { origin }^{b}}{\text { Geographic }}$ & $\begin{array}{c}\text { rDNA/EcoRIc } \\
\text { RFLP }\end{array}$ & 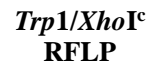 & $\begin{array}{c}\text { E18 } \\
\text { sequences }^{\mathrm{d}}\end{array}$ & $\mathrm{VCG}^{\mathrm{c}}$ \\
\hline 149 & $\mathrm{BC}$ & 2.2 & 1.5 & - & 4B \\
\hline 165 & $\mathrm{BC}$ & 2.2 & 1.5 & - & $4 B$ \\
\hline 166 & BC & 2.2 & 1.5 & - & $4 B$ \\
\hline 152 & OR & 2.2 & 1.5 & + & $4 B$ \\
\hline 193 & OR & 2.2 & 1.5 & + & $4 B$ \\
\hline 155 & OR & 2.2 & 1.5 & + & $4 B$ \\
\hline 157 & OR & 2.2 & 1.5 & + & $4 B$ \\
\hline 197 & ID & 2.2 & 1.5 & + & $4 B$ \\
\hline 201 & MT & 2.2 & 1.5 & + & 4B \\
\hline P3 & $\mathrm{OH}$ & 2.2 & 1.5 & + & $4 B$ \\
\hline P273 & $\mathrm{OH}$ & 2.2 & 1.5 & + & $4 B$ \\
\hline $62-8$ & NB & 2.2 & 1.5 & + & $4 B$ \\
\hline $101-1$ & NY & 2.2 & 1.5 & + & $4 B$ \\
\hline $102-1$ & NY & 2.2 & 1.5 & + & $4 B$ \\
\hline $105-1$ & NY & 2.2 & 1.5 & + & $4 B$ \\
\hline $11-11$ & $\mathrm{ME}$ & 2.2 & 1.5 & + & $4 B$ \\
\hline $16-1$ & ME & 2.2 & 1.5 & + & 4B \\
\hline $42-1$ & ME & 2.2 & 1.5 & + & $4 B$ \\
\hline $42-7$ & ME & 2.2 & 1.5 & + & $4 B$ \\
\hline $45-11$ & ME & 2.2 & 1.5 & + & $4 B$ \\
\hline $66-12$ & $\mathrm{ME}$ & 2.2 & 1.5 & + & $4 \mathrm{~A}$ \\
\hline $99-1$ & NY & 2.2 & 1.5 & + & $4 \mathrm{~A} / \mathrm{B}$ \\
\hline 170 & $\mathrm{BC}$ & 0.9 & 0.9 & - & $4 \mathrm{~A}$ \\
\hline 86 & WA & 0.9 & 0.9 & - & $4 \mathrm{~A}$ \\
\hline 87 & WA & 0.9 & 0.9 & - & $4 \mathrm{~A}$ \\
\hline 129 & WA & 0.9 & 0.9 & - & $4 \mathrm{~A}$ \\
\hline 131 & WA & 0.9 & 0.9 & - & $4 \mathrm{~A}$ \\
\hline 111 & MT & 0.9 & 0.9 & - & $4 \mathrm{~A}$ \\
\hline 108 & WY & 0.9 & 0.9 & - & $4 \mathrm{~A}$ \\
\hline 110 & WY & 0.9 & 0.9 & - & $4 \mathrm{~A}$ \\
\hline 90 & SD & 0.9 & 0.9 & - & $4 \mathrm{~A}$ \\
\hline 92 & SD & 0.9 & 0.9 & - & $4 \mathrm{~A}$ \\
\hline 97 & SD & 0.9 & 0.9 & - & $4 \mathrm{~A}$ \\
\hline $83-1$ & WI & 0.9 & 0.9 & - & $4 \mathrm{~A}$ \\
\hline 88 & WI & 0.9 & 0.9 & - & $4 \mathrm{~A}$ \\
\hline $21-18$ & MI & 0.9 & 0.9 & - & $4 \mathrm{~A}$ \\
\hline P103 & $\mathrm{OH}$ & 0.9 & 0.9 & - & $4 \mathrm{~A}$ \\
\hline P107 & $\mathrm{OH}$ & 0.9 & 0.9 & - & $4 \mathrm{~A}$ \\
\hline $30-6$ & NB & 0.9 & 0.9 & - & $4 \mathrm{~A}$ \\
\hline $66-13$ & ME & 0.9 & 0.9 & - & $4 \mathrm{~A}$ \\
\hline
\end{tabular}

${ }^{\mathrm{a}}$ Isolates with designations prefixed by $\mathrm{P}$ are from potato plants.

b OR, Oregon; ID, Idaho; MT, Montana; MI, Michigan; OH, Ohio; ME, Maine; BC, British Columbia; NY, New York; WA, Washington; WY, Wyoming; SD, South Dakota; WI, Wisconsin; NB, New Brunswick.

${ }^{\mathrm{c}}$ Hybridization probe/restriction enzyme combination used for the restriction fragment length polymorphism (RFLP) analysis. Sizes of polymorphic fragments $(\mathrm{kb})$ are indicated. Fragment sizes were estimated by agarose gel electrophoresis.

${ }^{\mathrm{d}}$ Presence $(+)$ or absence $(-)$ of E18 sequences determined by DNA blot hybridization of the E18 probe to EcoRI-digested genomic DNA.

e Data from reference 21. Isolate 99-1, previously classified as VCG 4A (21), was reclassified as VCG 4A/B (see Table 2).
pBluescript II KS (+). DIG-labeled pTZ19/VtITS probe was prepared as previously described (5). The E18 and $\operatorname{Trp} 1$ probes were prepared by polymerase chain reaction (PCR) amplification of the cloned sequences, using the PCR-DIG Labeling Kit (Roche Diagnostics, Laval QC), with 24-base primers complementary to the T7 and T3 promoter sequences of the plasmid vector and an annealing temperature of $65^{\circ} \mathrm{C}$.

\section{RESULTS}

Three $V$. dahliae strains of known VCG (5) were used as standards for the RFLP analyses. The ribosomal DNA sequence from V. tricorpus hybridized to two EcoRI fragments of genomic DNA from each of these strains, including one fragment of approximately $3.2 \mathrm{~kb}$ and one of either 2.2 or $0.9 \mathrm{~kb}$ (Fig. 1A). As shown in Fig. 1B, the $\operatorname{Trp} 1$ probe hybridized to two fragments of XhoI-digested genomic DNA from the same strains of $V$. dahliae, including one fragment of approximately 4.0 $\mathrm{kb}$ and one of either 1.5 or $0.9 \mathrm{~kb}$. The VCG 4A isolate Dvd-E6 contained the 0.9kb rDNA and 0.9-kb Trp 1 fragments. Both the VCG 2A isolate Dvd-T5 and the VCG $4 \mathrm{~B}$ isolate Dvd-2 contained the 2.2-kb rDNA fragment and the 1.5-kb Trp 1 fragment. As shown in Table 1, 18 of the potato isolates contained both the $0.9-\mathrm{kb}$ EcoRI rDNA and the 0.9-kb XhoI Trp 1 fragments; 22 of the isolates contained the 2.2-kb EcoRI rDNA and the 1.5-kb XhoI $\operatorname{Trp} 1$ fragments.

The repetitive DNA sequence E18 was present at low to moderate copy number in all but three isolates (BC isolates 149, 165, and 166) having the 2.2-kb EcoRI rDNA/1.5-kb XhoI Trp1 RFLP profile (Table 1; Fig. 2A, lanes 1 to 18; Fig. 2B, lanes 3 and 4) and absent from all isolates containing the 0.9-kb EcoRI rDNA and 0.9-kb XhoI Trp1 fragments (Table 1; Fig. 2B, lane 5). Four isolates from New York and Maine had E18 profiles that were highly similar (>80\% band identity) to those of isolates that are prevalent in some tomato and potato fields in southwestern Ontario (Fig. 2A, compare lanes 11 to 13, 18 , and 19; see also references $5,8,16$ ).

In recent studies, VCG $4 \mathrm{~A}$ isolates of $V$. dahliae have been found to lack E18 sequences and to contain the 0.9-kb EcoRI rDNA fragment $(5,16)$. Based on those data, the 18 isolates listed in Table 1 that contained the 0.9-kb rDNA and did not contain E18 sequences were predicted to be members of VCG 4A. Similarly, based on previous experiments showing that VCG 4B isolates are characterized by the 2.2-kb EcoRI rDNA fragment $(5,7,16)$, the 22 isolates with this RFLP (Table 1) were predicted to be members of VCG 4B.

The VCG predictions were correct for 38 of the 40 isolates, including all of those predicted to be in VCG 4A. However, while the rDNA RFLP profiles of isolates 
99-1 and 66-12 predicted their inclusion in VCG 4B (Table 1), both isolates had been previously assigned to VCG 4A (21). The vegetative compatibility of these isolates was therefore re-evaluated. The VCG 4A classification of isolate 66-12 was verified (Table 2). The vegetative compatibility classification of isolate 99-1 was less straightforward; nit mutants complemented some VCG 4B tester strains, but also complemented some VCG 4A testers. This isolate has therefore been tentatively reclassified VCG 4A/B (Table 2).

\section{DISCUSSION}

Molecular techniques, including RFLP and randomly amplified polymorphic DNA (RAPD) analysis, have been widely used to
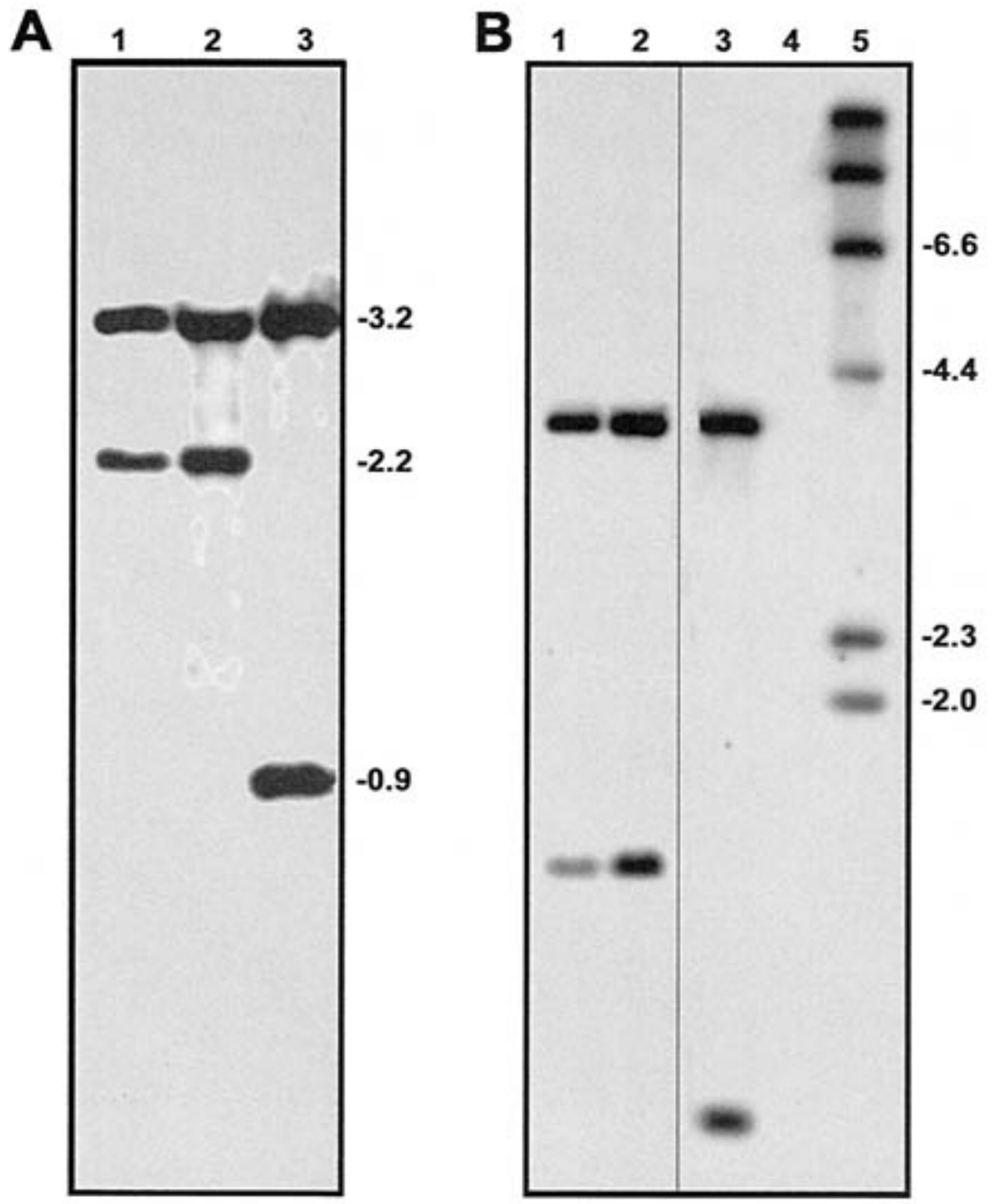

Fig. 1. DNA blots showing hybridization of the Trp 1 and rDNA probes to genomic DNA from isolates of Verticillium dahliae of vegetative compatibility groups 2A, 4A, and 4B. (A) DNA was digested with $E c o$ RI, and the blot was hybridized with the rDNA probe. Sizes of the hybridizing fragments $(\mathrm{kb})$ are indicated to the right of the blot. Lanes: 1, Dvd-2 (VCG 4B); 2, Dvd-T5 (VCG 2A); 3, Dvd-E6 (VCG 4A). Sizes of the fragments $(\mathrm{kb})$ are indicated to the right of the blot. (B) DNA was digested with XhoI, and the blot was hybridized with the Trp 1 probe. Lanes: 1, Dvd-T5 (VCG 2A); 2, Dvd-2 (VCG 4B); 3, Dvd-E6 (VCG 4A); 4, no DNA; 5, DIG-labeled Lambda/HindIII molecular markers. Sizes of markers $(\mathrm{kb})$ are indicated to the right of the blot. differentiate $V$. dahliae from other Verticillium species $(15,17)$ and to assess genetic diversity within $V$. dahliae $(2,5,8,11,16$, $18,19,24)$. With few exceptions, variation at the molecular level has not been correlated with aggressiveness, host, or geographic origin $(2,5,8,11,16,18,19,24)$.

In the case of vegetative compatibility, few data are available to adequately assess the relationship(s) between VCG and molecular variation. VCGs $2 \mathrm{~A}, 2 \mathrm{~B}$, and $4 \mathrm{~B}$ have been previously shown to be genetically heterogeneous groups comprised of isolates that may be further differentiated by their host range, aggressiveness on cotton, pathogenicity to tomato, or arrays of repetitive DNA sequences $(3,5,8,12,16)$. The data presented in the current study suggest that VCG 4A includes at least two genetically distinct types of isolates, one of which is characterized by the $0.9-\mathrm{kb}$ EcoRI/rDNA and 0.9-kb XhoI/Trp 1 markers and is prevalent across North America $(16,21)$. The results of this study also indicate that rDNA or Trp 1 marker analysis can be used to rapidly identify this VCG 4A genotype within collections of $\mathrm{V}$. dahliae obtained from soil or various potato tissues. It may also be possible in the future to exploit the polymorphisms at the rDNA or Trp1 loci, to develop a PCRRFLP assay(s) for diagnostic purposes.

The results of the VCG retests for isolate 99-1 (Table 2) highlight one of the potential difficulties in using vegetative compatibility to classify isolates. The RFLP analysis has several advantages over vegetative compatibility analysis; it is faster, less labor intensive, and less subject to variables inherent in the latter, such as the inability to obtain nit mutants or variation in the strength of complementation reactions with different tester strains. However, the utility of the rDNA and $\operatorname{Tr} p 1$ markers also has its limitations. Since no polymorphisms at the rDNA and Trp 1 loci have been identified between VCG 4B isolates and isolates of vegetative compatibility groups 1, 2A, 2B, 3, and 4A/B (Fig. 1, data not shown, and references 5,7), these markers cannot be used to definitively identify isolates within VCG 4B. Similarly, because E18 sequences are absent from some VCG 4B isolates (Table 1) and present in some isolates of VCGs $2 \mathrm{~A}$ and $2 \mathrm{~B}$ (Fig. 2A, lane 21, and data not

Table 2. Reassessment of vegetative compatibility groups of 99-1 and 66-12 isolates of Verticillium dahliae ${ }^{\text {a }}$

\begin{tabular}{|c|c|c|c|c|c|c|}
\hline \multirow[b]{2}{*}{ Isolate } & \multicolumn{5}{|c|}{ Tester strains } & \multirow[b]{2}{*}{ VCG } \\
\hline & $\begin{array}{c}\text { VCG 4B } \\
\text { Dvd-3 }\end{array}$ & $\begin{array}{c}\text { VCG 4B } \\
\text { MT }\end{array}$ & $\begin{array}{l}\text { VCG 4A } \\
\text { Dvd-E6 }\end{array}$ & $\begin{array}{c}\text { VCG 4A } \\
\text { BB }\end{array}$ & $\underset{\text { CW }}{\operatorname{VCG} 4 \mathbf{A} / \mathbf{B}^{\mathrm{b}}}$ & \\
\hline $99-1$ & + & $+/-c$ & - &,$++/-^{c}$ & + & $4 \mathrm{~A} / \mathrm{B}$ \\
\hline $66-12$ & - & - & + & + & + & $4 \mathrm{~A}$ \\
\hline
\end{tabular}

${ }^{a}$ Strength of the complementation reaction is indicated as strong (+), weak (+/-), or not detectable (-) according to references 9 and 10 . Data are from at least two tests between complementary mutants. In pairings where the amount of prototrophic growth varied between experiments, all types of interactions have been indicated.

b $4 \mathrm{~A} / \mathrm{B}$ designation indicates ability to complement both $4 \mathrm{~A}$ and $4 \mathrm{~B}$ isolates.

${ }^{\mathrm{c}}$ Prototrophic growth developed over 2- to 3-week period. 
shown), their presence is not a diagnostic marker for VCG 4B. In most cases it would therefore be necessary to use VCG and/or other molecular markers to further classify isolates having the 2.2-kb rDNA/1.5-kb Trp 1 polymorphisms.

Five E18 RFLP profiles were detected among the VCG $4 \mathrm{~B}$ and $4 \mathrm{~A} / \mathrm{B}$ isolates (isolates having $>80 \%$ identical bands were considered to have the same profile). Of particular interest was the observation that the E18 profiles of three New York isolates (101-1, 102-1, and 105-1) and one Maine isolate (11-11) were highly similar to that of the Ontario isolate Dvd-2 (Fig. 2) and to those of other isolates prevalent in Ontario potato and tomato fields $(8,16)$. It has recently been proposed that isolates of this type have been distributed throughout Ontario with seed potato $(7,8)$. Although only a small number of isolates from potato seed tubers were characterized in the present study, the data presented here are consistent with that hypothesis. More extensive studies will be required to determine the extent to which this genotype has been distributed across North America.

\section{ACKNOWLEDGMENTS}

We thank S. Grant for technical assistance, S. Evans for preparation of the figures, and M. Neumann for comments on the manuscript.

\section{LITERATURE CITED}

1. Botseas, D. D., and Rowe, R. C. 1994. Development of potato early dying in response to infection by two pathotypes of Verticillium dahliae and co-infection by Pratylenchus penetrans. Phytopathology 84:275-282.

2. Carder, J. H., and Barbara, D. J. 1991. Molecular variation and restriction fragment length polymorphisms (RFLPs) within and between six species of Verticillium. Mycol. Res. 95:935-942.

3. Daayf, F., Nicole, M., and Geiger, J. P. 1995. Differentiation of Verticillium dahliae populations on the basis of vegetative compatibility and pathogenicity on cotton. Eur. J. Plant Pathol. 101:69-79.

4. Dobinson, K. F. 1995. Genetic transformation of the vascular wilt fungus Verticillium dahliae. Can. J. Bot. 73:710-715.

5. Dobinson, K. F., Patterson, N. A., White, G. J., and Grant, S. 1998. DNA fingerprinting and vegetative compatibility analysis indicate multiple origins for Verticillium dahliae race 2 tomato isolates from Ontario, Canada. Mycol. Res. 102:1089-1095.

6. Dobinson, K. F., Tenuta, G. K., and Lazarovits, G. 1996. Occurrence of race 2 of Verticillium dahliae in processing tomato fields in southwestern Ontario. Can. J. Plant Pathol. 18:55-58.

7. Harrington, M. A. 1999. Cultural practices and Verticillium dahliae populations in southwestern Ontario processing tomato fields. M.Sc. thesis. University of Western Ontario, London, ON.

8. Harrington, M. A., and Dobinson, K. F. 2000. Influences of cropping practices on Verticillium dahliae populations in commercial proc- essing tomato fields in Ontario. Phytopathology. 90:1011-1017.

9. Joaquim, T. R., and Rowe, R. C. 1990. Reassessment of vegetative compatibility relationships among strains of Verticillium dahliae using nitrate-nonutilizing mutants. Phytopathology 80:1160-1166.

10. Joaquim, T. R., and Rowe, R. C. 1991. Vegetative compatibility and virulence of strains of Verticillium dahliae from soil and potato plants. Phytopathology 81:552-558.

11. Koike, M., Watanabe, M., Nagao, H., and Ohshima, S. 1995. Molecular analysis of Japanese isolates of Verticillium dahliae and V. albo-atrum. Lett. Appl. Microbiol. 21:7578.

12. Korolev, N., Katan, J., and Katan, T. 2000 Vegetative compatibility groups of Verticil lium dahliae in Israel: Their distribution and association with pathogenicity. Phytopathology 90:529-536.

13. Leslie, J. F. 1993. Fungal vegetative compatibility. Annu. Rev. Phytopathol. 31:127-150.

14. Leslie, J. F., and Zeller, K. A. 1996. Heterokaryon incompatibility in fungi-more than just another way to die. J. Genet. 75:415424.

15. Moukhamedov, R., Hu, X., Nazar, R. N., and Robb, J. 1994. Use of polymerase chain reaction-amplified ribosomal intergenic sequences for the diagnosis of Verticillium tricorpus. Phytopathology 84:256-259.

16. Mpofu, S. 1999. Population biology and management of Verticillium dahliae in potato fields in Ontario. Ph.D. diss. University of Guelph, Guelph, ON

17. Nazar, R. N., Hu, X., Schmidt, J., Culham, D., and Robb, J. 1991. Potential use of PCR-am-
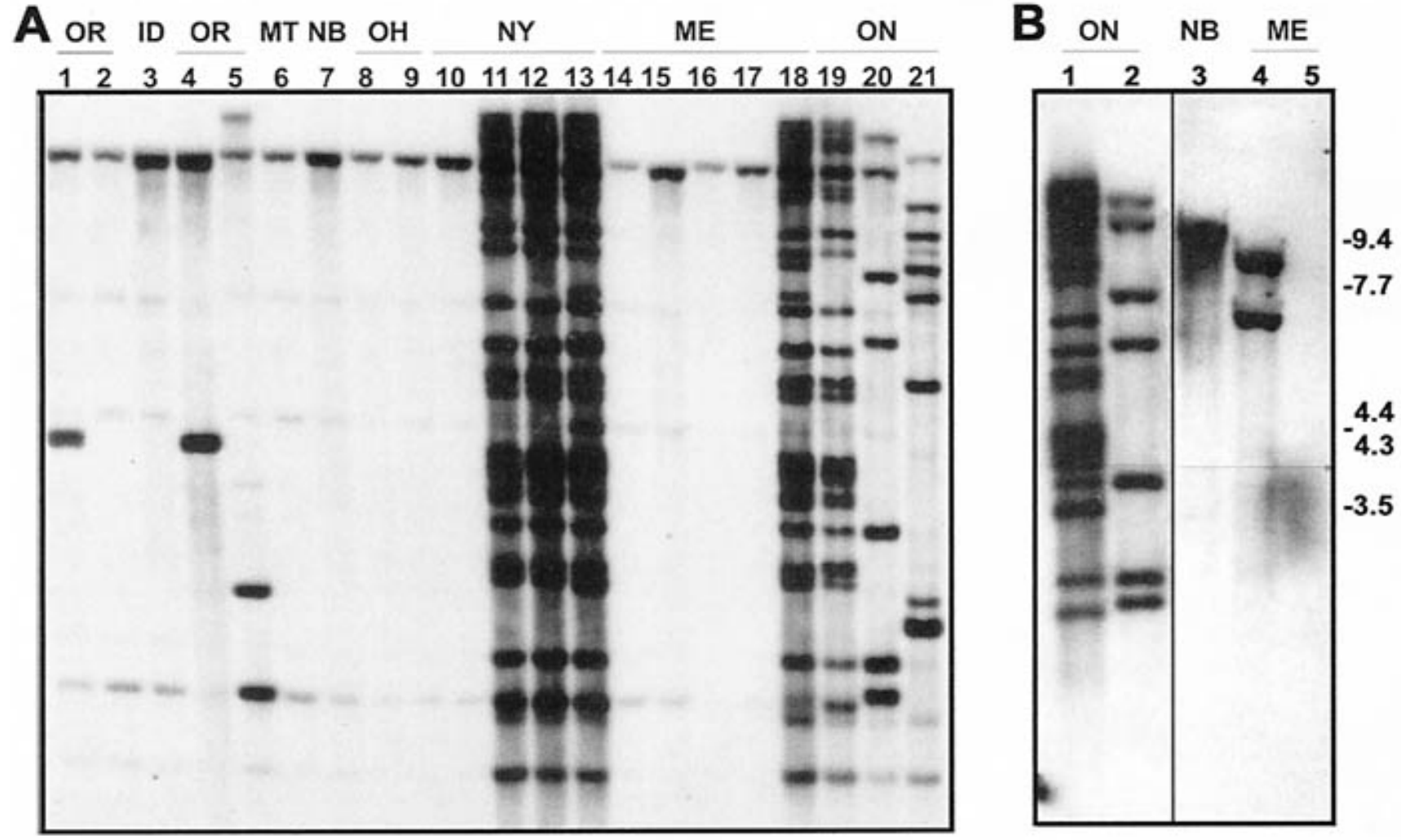

Fig. 2. DNA blots showing hybridization of probe E18 to genomic DNA from potato isolates of Verticillium dahliae. Genomic DNA from all E18containing isolates listed in Table 1 and from VCG 4A isolate 66-13, which does not contain E18 sequences, was digested with EcoRI, and the blots were hybridized with DIG-labeled probe. (A) Lanes: 1, 2, 4, and 5, Oregon isolates 157, 193, 155, and 152, respectively; 3, Idaho isolate 197; 6, Montana isolate 201; 7, New Brunswick isolate 62-8; 8 and 9, Ohio isolates P3 and P273; 10 to 13, New York isolates 99-1, 101-1, 102-1, and 105-1; 14 to 18, Maine isolates 16-1, 42-1, 42-7, 45-11, and 11-11; 19 to 21, Ontario isolates Dvd-2 (VCG 4B), Dvd-3 (VCG 4B), and Dvd-T5 (VCG 2A). (B) Lanes: 1 and 2, Ontario isolates Dvd-2 and Dvd-3; 3, New Brunswick isolate 62-8; 4 and 5, Maine isolates 66-12 and 66-13. Ethidium bromide staining of the gels indicated that equivalent amounts of DNA were in each lane (not shown). Sizes of molecular weight standards (kb) are indicated to the right of the blot. 
plified ribosomal intergenic sequences in the detection and differentiation of verticillium wilt pathogens. Physiol. Mol. Plant Pathol. 39:1-11.

18. Okoli, C. A. N., Carder, J. H., and Barbara, D. J. 1993. Molecular variation and sub-specific groupings within Verticillium dahliae. Mycol. Res. 97:233-239.

19. Okoli, C. A. N., Carder, J. H., and Barbara, D. J. 1994. Restriction fragment length polymorphisms (RFLPs) and the relationships of some host-adapted isolates of Verticillium dahliae. Plant Pathol. 43:33-40.

20. Omer, M., Beery, W., Johnson, D., and Rowe,
R. C. 1997. Vegetative compatibility among isolates of Verticillium dahliae from potato seed tubers and stems from the western USA. Phytopathology 87:S72.

21. Omer, M. A., Johnson, D. A., and Rowe, R. C. Recovery of Verticillium dahliae from North American certified seed potatoes and characterization of strains by vegetative compatibility and aggressiveness. Am. J. Potato Res. In press.

22. Patterson, N. A., and Dobinson, K. F. 1998. Isolation by genomic subtraction of subspecies-specific DNA probes from Verticillium dahliae. Fung. Genet. Newslett. 45:41-42.
23. Powelson, M. L., and Rowe, R. C. 1993 Biology and management of early dying of potatoes. Annu. Rev. Phytopathol. 31:111126.

24. Ramsay, J. R., Multani, D. S., and Lyon, B. R. 1996. RAPD-PCR identification of Verticillium dahliae isolates with differential pathogenicity on cotton. Austral. J. Agric. Res. 47:681-693.

25. Strausbaugh, C. A. 1993. Assessment of vegetative compatibility and virulence of Verticillium dahliae isolates from Idaho potatoes and tester strains. Phytopathology $83: 1253-1258$ 